\title{
Classical Soliton Theory for Studying the Dynamics and Evolution of in Network
}

\author{
Sergey Belyakin ${ }^{*}$ and Sergey Shuteev ${ }^{1,2}$ \\ ${ }^{1}$ Department of General Physics, Physics Faculty, Lomonosov Moscow State University, Moscow, Russia. \\ ${ }^{2}$ Laboratory of dynamic systems, Physics Faculty, Lomonosov Moscow State University, Moscow, Russia.
}

*Corresponding author: Sergey Belyakin, Emeritus Professor, McGovern Medical School, 6431 Fannin Houston, Texas.

Received date: July 08, 2021; Accepted date: July 20, 2021; Published date: July 31, 2021

Citation: Sergey Belyakin and Sergey Shuteev (2021). Classical Soliton Theory for Studying the Dynamics and Evolution of in Network. J Clinical Research and Reports, 8(4); DOI:10.31579/2690-1919/186

Copyright: () 2021, Sergey Belyakin. This is an open access article distributed under the Creative Commons Attribution License, which permits unrestricted use, distribution, and reproduction in any medium, provided the original work is properly cited.

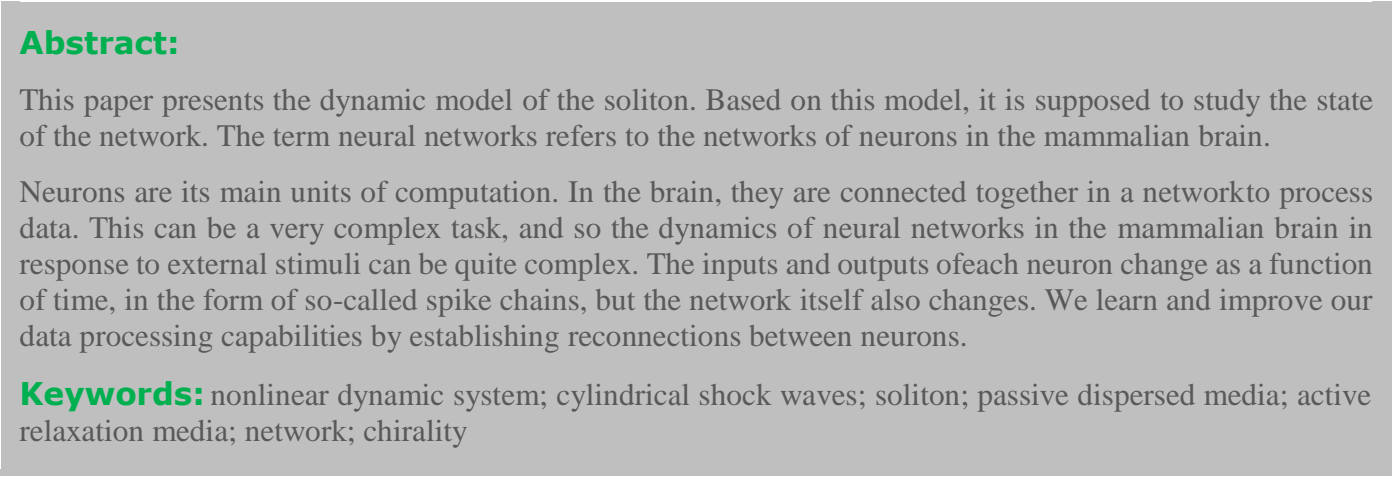

\section{Introduction}

The term neural networks refers to the networks of neurons in the mammalian brain.

Neurons are its main units of computation. In the brain, they are connected together in a networkto process data. This can be a very complex task, and so the dynamics of neural networks in the mammalian brain in response to external stimuli can be quite complex. The inputs and outputs ofeach neuron change as a function of time, in the form of so-called spike chains, but the network itself also changes. We learn and improve our data processing capabilities by establishing reconnections between neurons [1-3]. The training set contains a list of input data sets along with a list of corresponding target values that encode the properties of the input data that the network needs to learn. To solve such associative problems, artificial neural networks can work well-when new data sets are governed by the same principles that gave rise to the training data [4].

\section{Neural networks}

The mammalian brain is made up of different areas that perform different tasks. The cortex is the outer layer of the mammalian brain. We can think of it as a thin sheet ( 2 to $5 \mathrm{~mm}$ thick) that folds on its own to increase its surface area. The cerebral cortex is the largest and most developed part of the human brain. It contains a large number of nerve cells, neurons. The human cortex contains about 1010 neurons. They are connected by nerve threads (axons) that branch out and end in synapses. These synapses are connections to other neurons. Synapses connect to dendrites, branched extensions of the body of a nerve cell designed to receive input signals from other neurons in the form of electrical signals. A neuron in the human brain can have thousands of synaptic connections to other neurons. The resulting network of connected neurons in the cortex is responsible for processing visual, audio, and sensory data. Figure 1 Neuronsin the cerebral cortex (the outer layer of the brain, the largest and most developed part of the human and mammalian brain). 

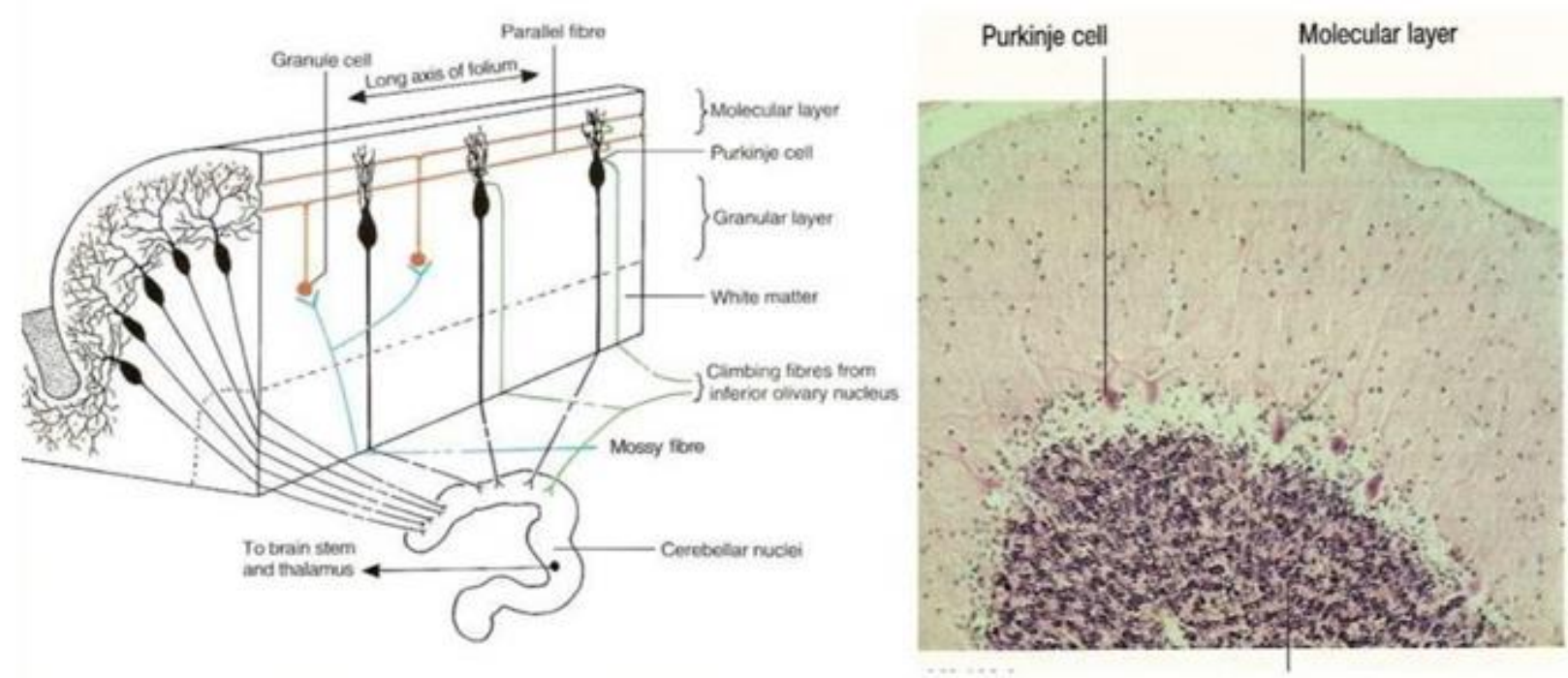

Figure 1. Neurons in the cerebral cortex (the outer layer of the brain, the largest and most developed part of the human and mammalian brain).

Figure 2, shows a more schematic view of the neuron. The information is processed from left to right. On the left are the dendrites that receive the signals and connect to the cell body of the neuron, where the signal is processed. The right part of the picture shows the axon through which the output is directed to the dendrites of other neurons.

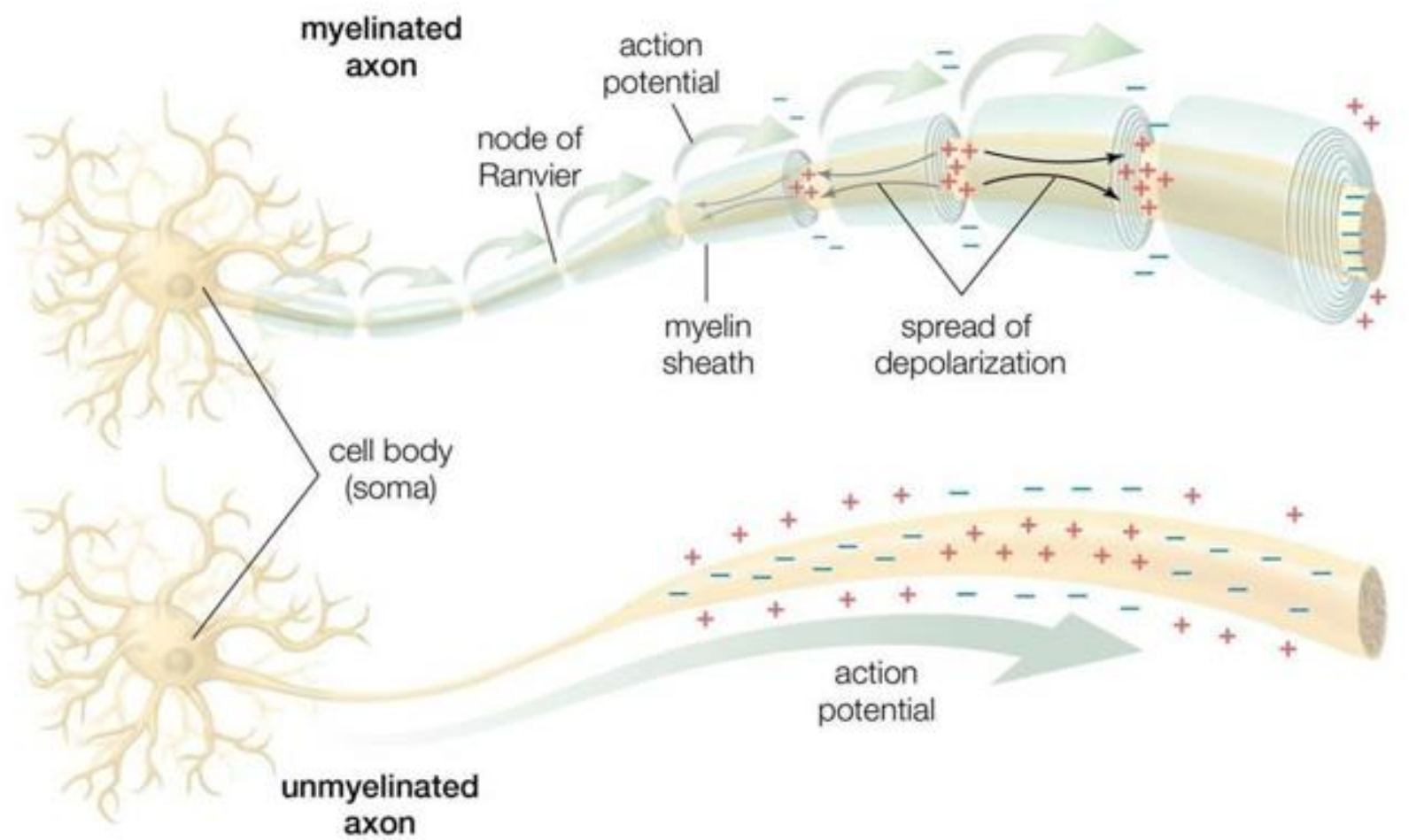

Figure 2. Schematic representation of a neuron. Dendrites receive input signals in the form of electrical signals through synapses. The signals are processed in the cell body of the neuron. The output signal is transmitted from the body of the nerve cell to other neurons via the axon.

The information is transmitted as an electrical signal. The information is transmitted as an electrical signal. Figure 3, shows a Schwann cell, which can be in a neutral state and create a left positive or right negative chirality on the axon. 


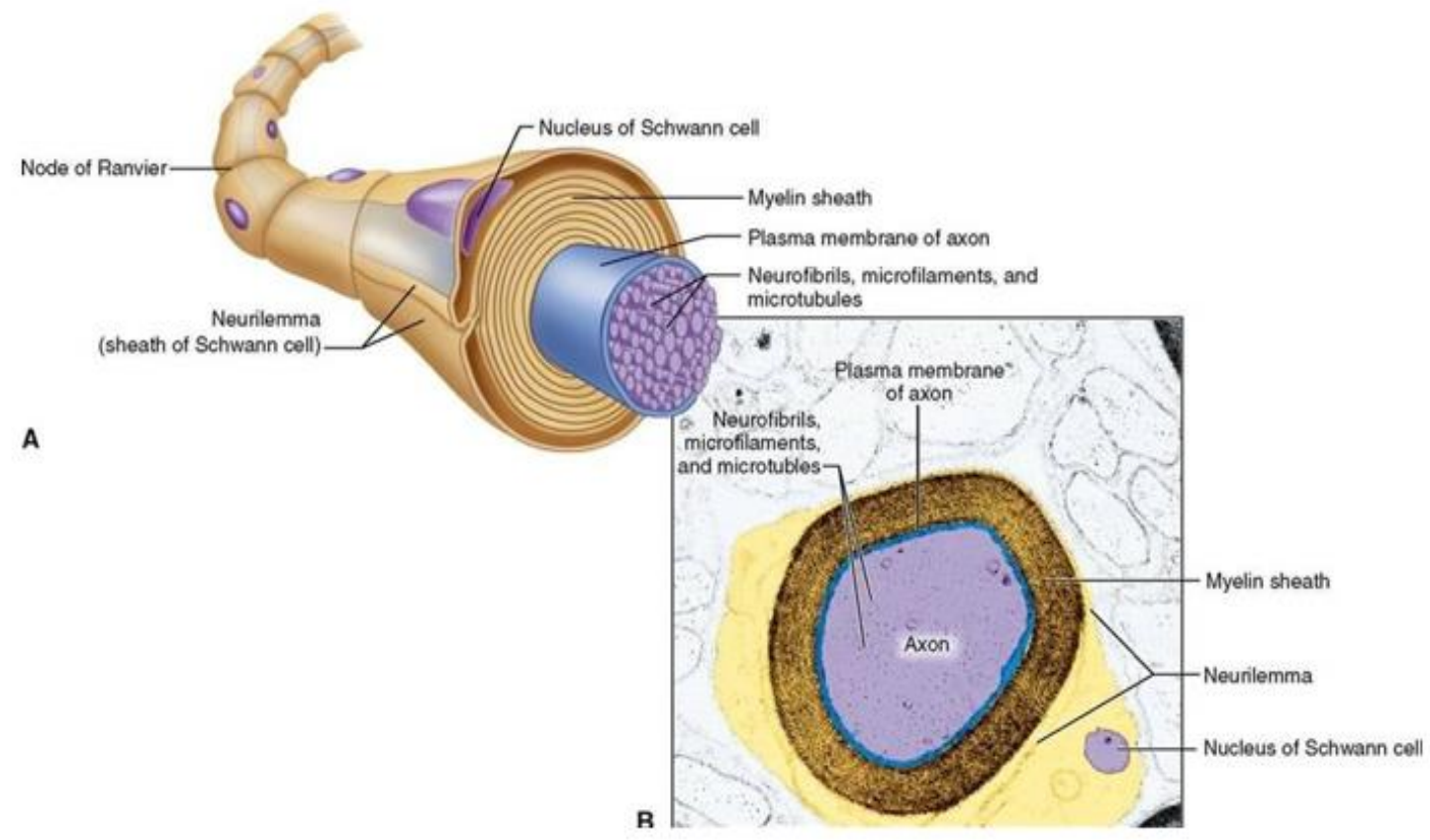

Figure 3. Shows a Schwann cell, which can be in a neutral state and create a left positive or right negative chirality on the axon.

Figure 4, shows an example of the time series of theelectric potential of a pyramidal neuron [5]. The time series consists of an intermittent series of electric potential jumps. Periods of rest without spikes occur when the neuron is inactive, and during periods rich in spikes, the neuron is active. Figure 4D, Temporary portraits of the system (1).
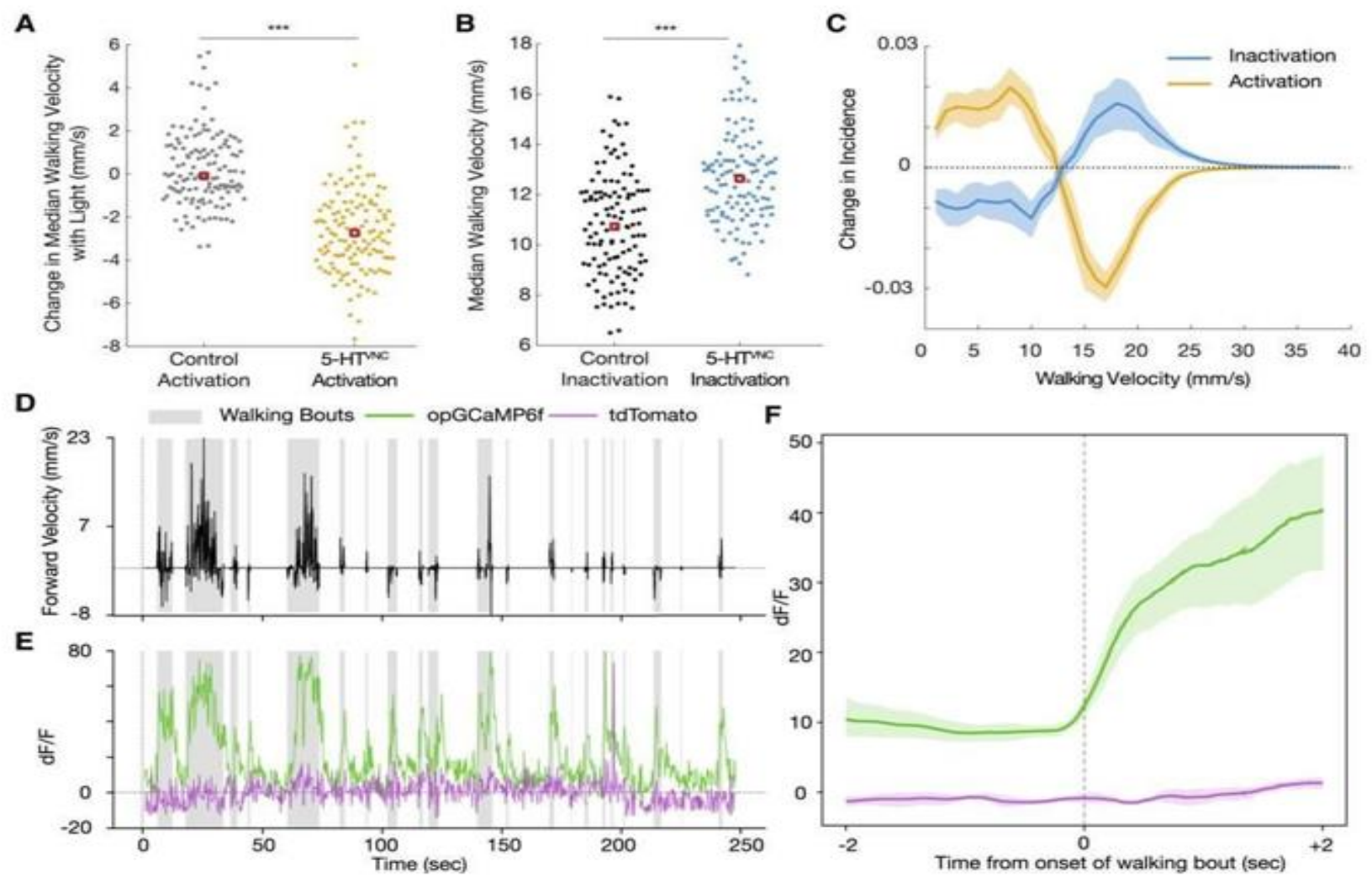

Figure 4. Shows an example of the time series of the electric potential of a pyramidal neuron. series consists of an intermittent series of electric potential jumps. 


\section{The mathematical dynamic model of the soliton}

The mathematical dynamic model of the soliton is represented by the equation (1) $[6,7]$.

$$
\begin{aligned}
& \dot{x}=a x\left(1-a_{3} y-a_{1} x\right)(1+k \sin (\omega t), \\
& \dot{y}=b y\left(1-a_{3} x-a_{2} y\right)(1+k \cos (0 t), \\
& \dot{z}=x y \operatorname{sch} x \operatorname{sch} y \sin \omega t \cos \omega t .
\end{aligned}
$$

a

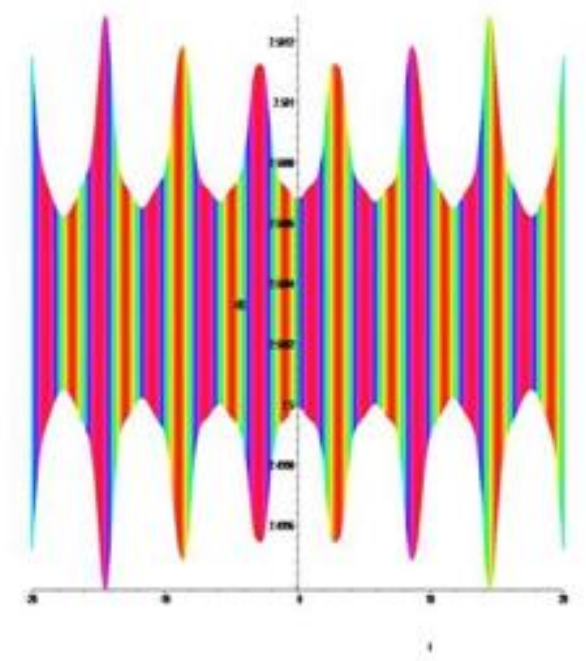

\section{Results}

The active states of the system are shown in Figure 5a, and their active states are shown in Figure 2(top) in yellow and Figure 4(E,F) in green.

The active states of the system are shown in Figure 5b, and their active states are shown inFigure 2(bottom) in yellow and Figure 4E in purple. Creates a continuous chaotic modulation.

Time portraits of the system (1) are shown in Figure 5(a), active with positive $\mathrm{a}=1.0, \mathrm{a} 1=0.2, \mathrm{a} 2=0.1, \mathrm{a} 3=1.0, \mathrm{~b}=-2.0, \mathrm{k}=0.045, \omega=64 \pi$ and negative $\mathrm{a}=-1.0, \mathrm{a} 1=0.2, \mathrm{a} 2=-0.1, \mathrm{a} 3=1.0, \mathrm{~b}=2.0, \mathrm{k}=0.045, \omega$ $=64 \pi$ chirality.

Figure $5(\mathrm{~b})$, passive positive $\mathrm{a}=0.09, \mathrm{a} 1=0.2, \mathrm{a} 2=0.1, \mathrm{a} 3=1.0, \mathrm{~b}=-$ $0.09, \mathrm{k}=0.045, \omega=64 \pi$ and negative $\mathrm{a}=-0.09, \mathrm{a} 1=0.2, \mathrm{a} 2=-0.1, \mathrm{a} 3=$ $1.0, \mathrm{~b}=0.09, \mathrm{k}=0.045, \omega=64 \pi$ chirality:

b

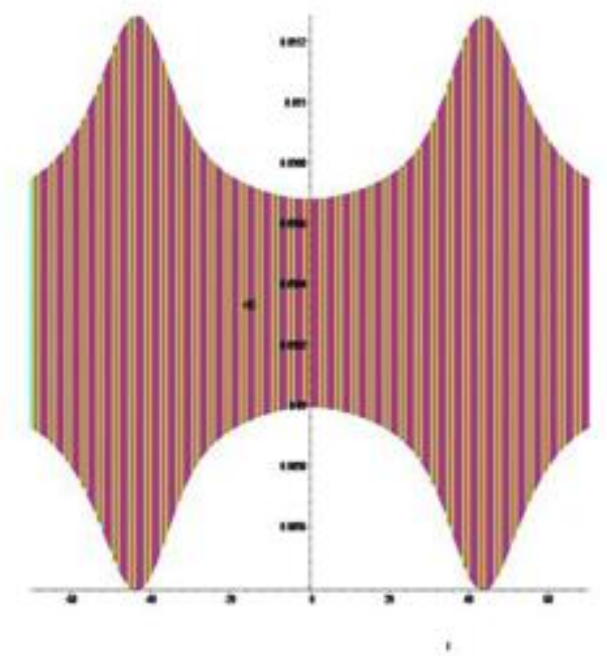

Figure 5. Temporary portraits of the system with chirality. (1) at : a) $x 0=0.4, y 0=0.4, z 0=2.5, b$ ) $x 0=0.4, y 0=0.4, z 0=0.09$.

The inactive state of the system is shown in Figure 6a its active state is shown in Figure 4(A,C) inyellow. It is presented in a limited time frame.

The inactive state of the system is shown in Figure $6 \mathrm{~b}$ its inactive state is shown in Figure 4(B,C)in blue and Figure 4F in purple. It is presented in a limited time frame.

Time portraits of the system (1) are shown in Figure 6(a) active with positive $a=1.0, a_{1}=0.2, a_{2}=0.1, a_{3}=1.0, b=2.0, k=0.045, \omega=64 \pi$ and negative $a=-1.0, a_{1}=0.2, a_{2}=-0.1, a_{3}=1.0, b=-2.0, k=0.045, \omega=64 \pi$ lack of chirality.

Figure 6(b) passive positive $a=0.09, a_{1}=0.2, a_{2}=0.1, a_{3}=1.0, b=0.09$, $k=0.045, \omega=64 \pi$ and negative $a=-0.09, a_{1}=0.2, a_{2}=-0.1, a_{3}=1.0, b$ $=-0.09, k=0.045, \omega=64 \pi$ lack of chirality: 

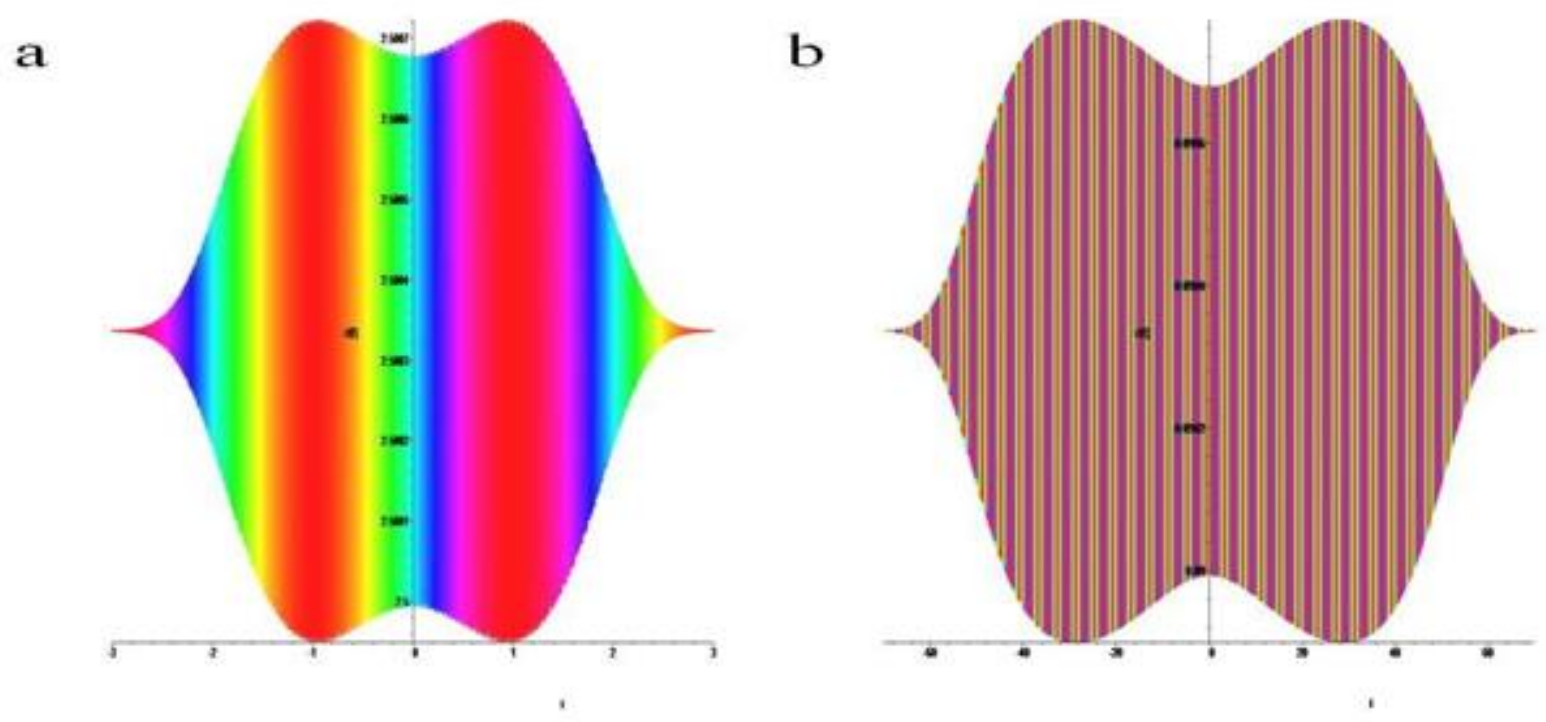

Figure 6. Temporary portraits of the system with no chirality. (1) at : a) $x 0=0.4, y 0=0.4, z .0=2.5, b) x 0=0.4, y 0=0.4, z 0=0.09$.

\section{Summary:}

Artificial neural networks use a highly simplified model for the fundamental computing unit-the neuron. In its simplest form, the model is simply a binary threshold unit. The networkperforms these calculations sequentially. Usually, discrete sequences of calculation time steps are considered, $\mathrm{t}=0,1,2,3$,.Either all neurons are updated simultaneously at one time step (synchronous update), or only one selected neuron is updated (asynchronous update) [8-19]. Weproposed a different approach to use the wave-soliton approach, taking into account chirality. Inthe presence of different chirality, three states are possible, with positive chirality, the signal is transmitted without loss, with negative chirality, the signal creates pulsations in certain parts of the axon. In the absence of a signal, a chaotic self-excitation is observed in the axon. A run a way with no chirality exists for a short time and represents a stop signal. The conclusion is that the soliton model can be used to study the behavior of an individual axon.

\section{References:}

1. Belyakin S.T, Shuteev S.A., (2020). Analysis of dynamics of infected active and uninfected active populations leading to pandemics using a discrete model of two interacting pacemakers taking into account the time of refractoriness. "Journal of Nanosciences Research \& Reports". Coventry, West Midlands, US: v.2, №4, 2020, P.1- 4 .

2. Belyakin S.T, Shuteev S.A., (2020). The generalized model N pacemaker curve phase response of the Atria, ventricular fibliration and AB - blockade. "Global Journal of Nanomedicine". US: v.13, № 3, 2020, P.001 - 009.

3. Belyakin S.T, Shuteev S.A., (2019). Application of sampling methods to nanostructures on the example of cellular structures of cardiac arrhythmia dynamics. "Advances in Nanoscience and Nanotechnology journal". US: v.3, №3, 2019, P.1-6.

4. Lecun, A., Bengio, Y., Hinton, G., (2015). Deep learning. "Nature". US: v.521, 2015, P.463.

5. Gabbiani, F., Metzner,W., (1999). Encoding and processing of sensory information in neuronal spike trains. "Journal of Experimental Biology". US: v.202, №10, 1999, P.1267.

6. Belyakin S.T, Shuteev S.A., (2020). Classical soliton theory for studying the dynamics and evolution of cylindrical shock waves in passive dispersed and active relaxation media. "PAST KNOWLEDGE PEOPLE, Journal of Applied Material Science \& Engineering Research", US: v.4, №4, 2020, P.157- 159.

7. Belyakin S.T, Shuteev S.A., (2021). Study of the dynamics and evolution of fibrillation in the human heart by the classical soliton model. "Journal of Cardiology Interventions", US: v.2, №1, 2021, P.1.1006 (1) - 1.1006(4).

8. Borg-Graham L., (1999). Interpretations of data and mechanisms for hippocampal pyramidal cell models. In: Cerebral Cortex. "Plenum Press", US: v.13, 1999, P.19-138.

9. Chizhov A.V., Graham L.J., (2007). Population model of hippocampal pyramidal neurons, linking a refractory density approach to conductance-based neurons. "Phys. Rev. E", US: v.75, 2007, P.011924.

10. ChizhovA.V., Graham L.J., (2008). Efficient evaluation of neuron populations receiving colorednoise current based on a refractory density method. "Phys. Rev. E", US: v.77, 2008, P.011910.

11. Chizhov A.V., Rodrigues S., Terry J.R., (2007). A comparative analysis of a firing-rate model and a conductance-based neural population model. "Physics Letters A", US: 369(1-2), 2007, P.3136.

12. Cruikshank S.J., Lewis T.J., Connors B.W., (2007). Synaptic basis for intense thalamocortical activation of feedforward inhibitory cells in neocortex. "Nature Neuroscience", US: 10(4), 2007, P.462-468.

13. Eggert J., van Hemmen J.L., (2001). Modeling Neuronal Assemblies: "Theory and Implementation. Neural Computation", US: 13, 2001, P.1923-1974.

14. Gerstner W., Kistler W.M., (2002). Spiking Neuron Models, Single Neurons, Populations, Plasticity. "Cambridge University Press", Cambridge, UK: 2002.

15. Kandel E.R., Schwartz J.H., Jessell T.M., (2000). "Principles of Neural Science. Fourth edition", McGraw-Hill: 2000, P.1414.

16. Karnup S., Stelzer A., (1999). Temporal overlap of excitatory and inhibitory afferent input in guinea-pig CA1 pyramidal cells. "J. Physiology", US: 516(2), 1999, P.485-504.

17. Kopell N., Ermentrout G.B., Whittington M.A., Traub, R.D., (2000). Gamma rhythms and beta rhythms have different 
synchronization properties. "Neurobiology", US: 97(4), 2000, P.1867- 1872.

18. Nykamp D., Tranchina D., (2000). A Population Density Approach That Facilitates Large-Scale Modeling of Neural Networks: "Analysis and an Application to Orientation Tuning. J.
Comput. Neuroscience", US: 8, 2000, P.19-50.

19. Omurtag A., Knight B.W., Sirovich L., (2000). On the simulation of large populations of neurons. "J. Comput. Neuroscience", US: 8, 2000, P.51-63.
This work is licensed under Creative Commons Attribution 4.0 License

To Submit Your Article Click Here: Submit Manuscript

DOI: $10.31579 / 2690-1919 / 186$
Ready to submit your research? Choose Auctores and benefit from:

* fast, convenient online submission

* rigorous peer review by experienced research in your field

* rapid publication on acceptance

* authors retain copyrights

* unique DOI for all articles

* immediate, unrestricted online access

At Auctores, research is always in progress.

Learn more www.auctoresonline.org/journals/journal-of-clinicalresearch-and-reports 